\title{
Application of a Commercial Real-Time RT-PCR Assay for Surveillance of Classical Swine Fever: Evaluation by Testing Sequential Tissue and Blood Samples
}

\author{
M. Tignon ${ }^{*}$, , G. Kulcsár ${ }^{2}$, K. Belák ${ }^{3}$, A. Haegeman ${ }^{1}$, T. Barna ${ }^{2}$, K. Fábián ${ }^{2}$, R. Lévai² , A. Farsang², \\ Y. Van der Stede ${ }^{4}$, R. Vrancken ${ }^{1}$ and F. Koenen ${ }^{1}$ \\ ${ }^{I}$ Veterinary and Agrochemical Research Centre (VAR), Department of Virology, Groeselenberg 99, B-1180 Brussels, \\ Belgium \\ ${ }^{2}$ Central Agricultural Office, Directorate for Veterinary Medicinal Products (DVMP), Szállás utca 8, H-1107 Budapest, \\ Hungary \\ ${ }^{3}$ National Veterinary Institute (NVI), Departments of Pathology and Virology, Ulls väg 2B, SE-751 89 Uppsala, Sweden \\ ${ }^{4}$ Veterinary and Agrochemical Research Centre (VAR), Coordination Centre for Veterinary Diagnostics, Groeselenberg \\ 99, B-1180 Brussels, Belgium
}

\begin{abstract}
The applicability of the commercial TaqVet CSFV real-time RT-PCR assay (TaqVet CSF) as a diagnostic tool for herd surveillance of classical swine fever (CSF) was evaluated in an experimental setup on a group of 28 pigs infected with a moderately virulent classical swine fever virus (CSFV) strain of wild boar origin ('11722-WIL'). Based on the viral distribution determined in tissue by the real-time RT-PCR assay (rRT-PCR), the tonsils were found the most suitable tissue for CSFV detection. In the tonsils, the viral genome was detected during the incubation phase, as early as 2 days post infection (dpi), and during the clinical phase until the end of the experiment (24 dpi). In blood, viral RNA detection was delayed by 2 days compared to the corresponding tonsils. Virus was irregularly detected in muscles, indicating the poor reliability of meat for CSFV monitoring. For surveillance programmes, the effectiveness of the rRT-PCR kit was also evaluated on blood samples collected at the scale of the animal group and compared to the individual diagnosis based on analysis of tonsils. The present study indicated that, at the very early stages of infection, comparable detection efficiency was achieved by using large numbers of blood samples or smaller number of tonsils. The increased size of sampling is necessary to compensate the lower viral load observed in blood. Based on these results, testing of blood can be proposed as an acceptable alternative to tonsils for herd surveillance with the TaqVet CSF kit, providing that extended sampling is undertaken.
\end{abstract}

\section{INTRODUCTION}

During the last decade the emergence or re-emergence of transboundary animal diseases, such as classical swine fever (CSF), and their severe socio-economic consequences in countries with industrialised animal production systems have focused increased attention on animal health issues in the European Union (EU) [1,2].

In the EU the measures to be applied in order to prevent, control and eradicate CSF have been harmonised for all member states by legislation in EU Directives 80/217/EEC and 2001/89/EC. The strategy is mainly based on a policy of non-vaccination of pig herds and the stamping out of infected and possibly infected contact and neighbouring pig herds. During previous outbreaks it has been shown that the early detection of the primary classical swine fever virus (CSFV) infected herd is crucial to minimise the size of an

*Address correspondence to this author at the Veterinary and Agrochemical Research Centre (VAR), Department of Virology, Groeselenberg 99, B1180 Brussels, Belgium; E-mail: Marylene.Tignon@var.fgov.be outbreak and to control the disease in large and dense pig populations $[1,3]$. As long as it remains undetected, the virus can spread freely in the susceptible pig population by direct animal contact and vehicle-borne indirect transmission (people, equipment, vehicles, artificial insemination,...) $[4$, $5]$.

The diagnosis of CSF in the field is difficult if nonspecific or mild clinical signs occur. Such a clinical picture is encountered with moderate to low virulent CSFV strains, like those isolated from outbreaks in wild boar and domestic pigs in Europe from the 1990s onwards [6-8]. In such situations, laboratory diagnostics based on virus isolation (VI) or on the detection of viral antigen, genome or specific antibodies are essential to confirm suspicious cases [9-11]. Tonsils or blood are generally taken as samples and targeted for diagnosis and surveillance programs [12-14]. Routine testing of meat has also been suggested due to the long-lasting virus infectivity in this material under cold storage conditions [1417]. Since the early 1990s the development of new molecular tests has led to an improved sensitivity in CSFV detection [12, 13, 18, 19]. Reverse-transcription PCR (RT-PCR) and, more recently, real-time RT-PCR (rRT-PCR) assays have 
permitted the detection of infection regardless of the clinical stage, starting from early infection, during the incubation phase and all along the clinical phase $[13,18]$. Moreover, the viral genome detection has been achieved regardless the course of CSF, even when mild forms of CSF occur, as well as at the seroconversion phase, in the presence of antibodies $[12,13,18]$. As a consequence, rRT-PCR is being more and more recommended for confirmatory diagnosis in individual animals and for herd surveillance $[12,13,18]$. Furthermore, the recent validation of two commercial kits for CSFV rRTPCR (TaqVet CSF from LSI and Adiavet CSF from ADIAGENE), confirming their sensitivity and specificity will facilitate the move to generalized molecular mass diagnostics [20]. However, in previous studies, the rRT-PCR was only evaluated on small groups of 5 to 8 experimentally infected pigs $[12,13,18]$. To date, the relevance of rRT-PCR assays for herd surveillance of CSF has not yet been investigated in large animal groups. Moreover, external factors affect the efficacy of virus detection, such as the strain virulence, the choice of the target biological material, like tonsils, blood or muscles, or the sampling strategy $[17,21]$. Their impact on rRT-PCR diagnosis has not yet been estimated at the level of a large infected animal group.

The aim of this study was the evaluation of the commercial TaqVet CSF rRT-PCR kit for application in CSF surveillance. For this purpose, the validated kit was evaluated in an experimental setup including 28 domestic pigs oronasally infected by a moderately virulent CSFV strain derived from wild boar. The efficacy of rRT-PCR virus detection was investigated both at individual and group level by testing tissue and blood samples sequentially collected with regard to the course of the disease and compared to conventional diagnostic methods like clinical examination, haematology, virus isolation and serology.

\section{MATERIAL AND METHODS}

\section{Experimental Design}

The animal experiment was conducted with the approval of the VAR and DVMP ethical committees. Upon arrival, 30 Kahyb breed pigs, two months of age and weighing approximately $12 \mathrm{~kg}$, were housed on a solid floor with wood shavings and kept under stable biosecure housing conditions in agreement with EU directive 91/630/EEC and its amendments 2001/88/EC and 2001/93/EC. The animals were fed ad libitum with standard commercial diet. All the pigs originated from the same herd and were negative for bovine viral diarrhoea virus (BVDV) and CSFV as well as for antibodies against them using standard diagnostic procedures.

After an acclimatising period of seven days, 28 pigs were oronasally infected with $10^{3.8} \operatorname{TCID}_{50}(2 \mathrm{ml})$ of the ' 11722 WIL' strain of CSFV (Day 0). This virus strain was originally isolated from a wild boar in Rhineland-Palatinate (Germany) and belongs to the genotype 2.3 (Rostock type) [8]. The inoculum, consisting of the original isolate passaged twice in porcine kidney cell cultures $\left(\mathrm{PK}_{15}\right)$, was kindly provided by Dr. V. Kaden (Friedrich-Loeffler-Institut, Germany). The isolate was shown to be free of African swine fever virus and BVDV by applying PCR methods [22, 23].

The animals were slaughtered by an intravenous pentobarbital injection, followed by exsanguination, in a random sequence determined at the beginning of the experiment. The two non-infected animals were slaughtered on the day of inoculation as negative controls; two infected animals on a daily basis during the first eight days post infection (dpi); on a two-day basis from 10 until $14 \mathrm{dpi}$; and finally at $17 \mathrm{dpi}$. Remaining animals either died spontaneously or were euthanized for ethical reasons when moribund at 20,23 and 24 dpi.

\section{Clinical Examination and Sample Collection}

The animals were clinically monitored using the scoring system developed by Mittelholzer et al. [24]. To minimise variation, the same person performed the clinical scoring and rectal temperature measurements on a daily basis before sample collection. Pigs were considered febrile when rectal temperatures exceeded $40^{\circ} \mathrm{C}$.

EDTA-treated blood and serum samples were collected during the experiment from all living animals on each slaughter day. At necropsy, tissue samples including tonsils, submandibular and mesenteric lymph nodes, thymus, heart, lungs, spleen, kidneys, ileum, quadriceps and longissimus dorsi muscles were aseptically collected. The EDTA-treated blood, sera and tissue samples were stored at $-80^{\circ} \mathrm{C}$ until analysis.

\section{Haematology}

The total number and differentiation of peripheral blood leucocytes (PBLs) was determined in EDTA-treated blood samples by using a Sysmex E-4000 automatic haemocytometer (Toa Medical Electronics, Kobe, Japan). From 0 until 12 dpi, data were collected from 10 animals and later from the remaining animals.

\section{Virological and Serological Analysis}

Virus isolation from tissue samples, EDTA-treated blood and sera was performed on semi-confluent monolayers of $\mathrm{PK}_{15}$ cells $[9,21]$. After 48 hours, the cells were fixed with isopropanol and stained with polyclonal fluoresceinconjugated anti-CSFV immunoglobulins. The presence of CSFV genome in EDTA-treated blood, sera and tissue samples was determined by using the commercially available TaqVet CSF real-time RT-PCR kit (termed simply as TaqVet CSF in the following) (Laboratoire Service International, Lissieu, France) after RNA extraction with an RNeasy kit (Qiagen Benelux B.V., Venlo, The Netherlands). In addition, positive rRT-PCR blood samples were evaluated in pools by the molecular assay. Pooled blood samples were obtained by mixing one positive and four negative samples before RNA extraction. The assays were performed using an ABI-PRISM 7900 HT machine (Applied Biosystems, Lennik, Belgium) and analysed by the Sequence Detection System 2.1. According to the manufacturer's specification, cycle threshold $(\mathrm{Ct})$ values lower than 45 were considered positive. However, $\mathrm{Ct}$ values higher than 40 were confirmed by an independent repetition.

Furthermore, samples with discrepant VI and rRT-PCR results at the later stages of infection were evaluated for the integrity of the viral genome using a panel of three gel-based RT-PCR tests amplifying parts of the NS2, NS3 and NS5A genes [25]. 
The CSFV specific antibody response was investigated with a virus neutralisation test [26] using the homologous strain and with a blocking antibody-ELISA test HerdChek CSFV (IDEXX Europe B.V., Schiphol-Rijk, The Netherlands).

\section{Statistical Analysis}

The data were presented as means and the corresponding standard deviation. Significance between mean values of PBL, neutrophil and lymphocyte cells was evaluated using the General Linear model procedure in SAS software (9.1.3, $\mathrm{SAS}, \mathrm{Inc})$. The null hypothesis was considered rejected at $\mathrm{P}$ $\leq 0.05$.

The relative sensitivity of the VI and rRT-PCR methods was evaluated at $2 \mathrm{dpi}$ until $7 \mathrm{dpi}$, assuming rRT-PCR as the reference method and fixing the number of false positive results at zero.

\section{RESULTS}

\section{Clinical Examination}

Before infection, the mean rectal temperature was $39.4^{\circ} \mathrm{C}$ (+/- 0.4) (Fig. 1). The first febrile animal was observed at 2 dpi. The mean temperature of the group reached $40.0^{\circ} \mathrm{C}(+/-$ $0.4)$ at $6 \mathrm{dpi}$ and its maximum $\left(40.8^{\circ} \mathrm{C}+/-0.6\right)$ at $12 \mathrm{dpi}$ when all the remaining animals became febrile. From 12 to $16 \mathrm{dpi}$, the fever decreased significantly $(\mathrm{P} \leq 0.014)$ to reach a mean value of $39.9^{\circ} \mathrm{C}(+/-0.2)$, after which it stabilised and persisted in the group until the end of the experiment (24 dpi).
The first positive clinical score was observed at $5 \mathrm{dpi}$ when one animal demonstrated a slight reduction in liveliness (Fig. 1). Mild clinical signs were observed from 8 until 19 dpi. Score values started to rise dramatically from 20 dpi $(7.5+/-2.1)$ until the end of the experiment (14.0). The clinical scores were distributed between the 10 evaluated parameters.

\section{Haematology}

The initial mean PBL population before infection was $22.9 \times 10^{3}$ cells $/ \mu 1\left(+/-7.0 \times 10^{3}\right)$ (Fig. 2). A significant decrease $(\mathrm{P} \leq 0.05)$ in the number of PBLs was detected from 3 dpi until 22 dpi compared to its initial value using the General Linear model procedure. At its lowest level (6 dpi), PBL population represented $31.8 \%$ of the initial population $(+/-$ $10.1 \%$ ). Leucopoenia was observed from 5 to $12 \mathrm{dpi}$ and corresponded with a decrease in both the lymphocyte and neutrophil populations, being more pronounced for the latter.

\section{Virus Detection in Tissue Samples}

As can be seen in Table 1, infection was first detected at 2 dpi with the TaqVet CSF. At 2, 3 and 4 dpi, the infection was demonstrated in only one animal of each slaughtered pair. Afterwards, the presence of virus was demonstrated in tissues collected from all slaughtered animals except one pig at $7 \mathrm{dpi}$.

The rRT-PCR assay generally detected virus 1 to 3 days before VI, depending on the tissue investigated. From 6 dpi onwards, all tissue samples collected from the infected animals, except the muscles, were positive with the TaqVet CSF whereas the VI method did not detect virus before 8 dpi.

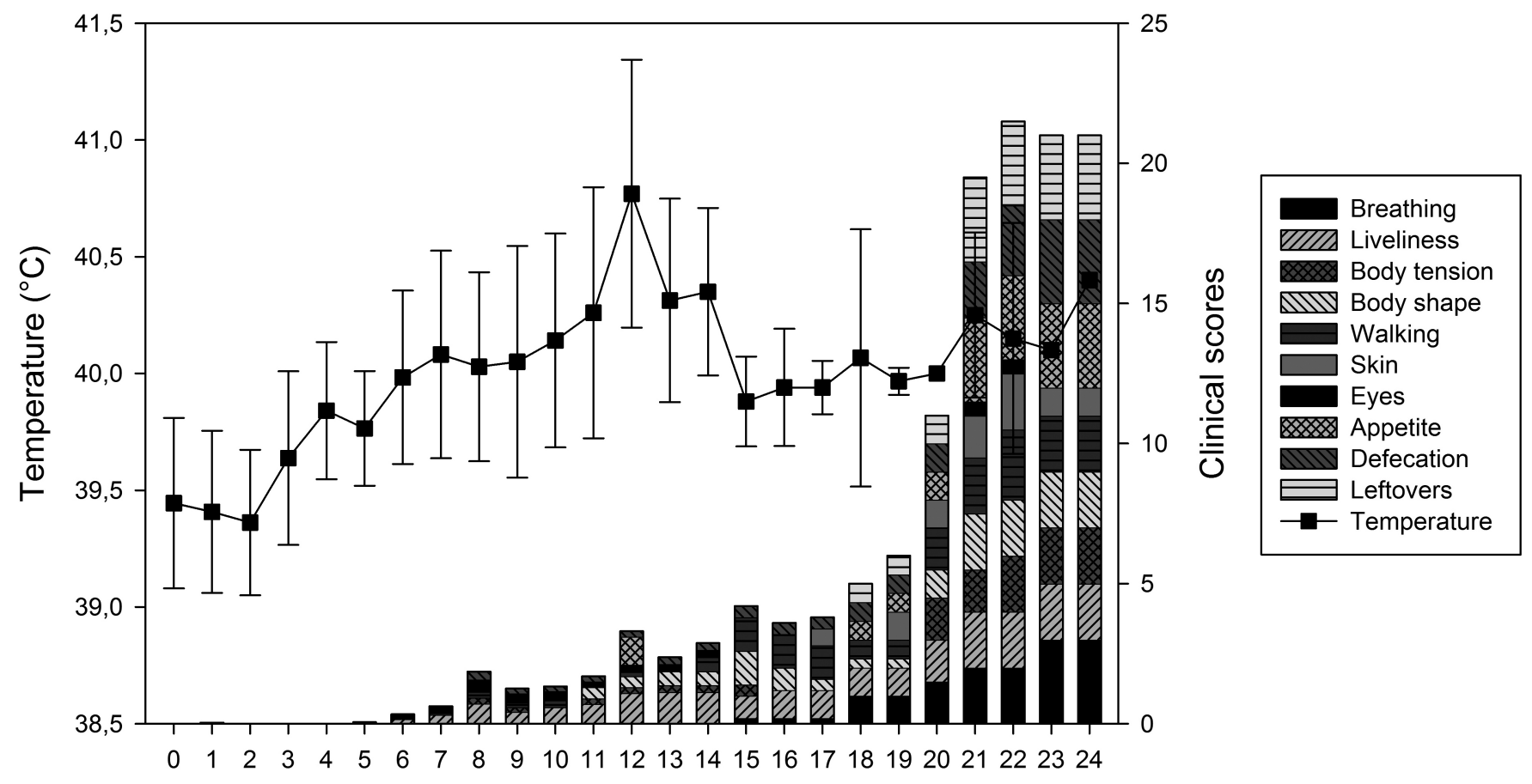

Days post infection

Fig. (1). Development of mean temperatures and clinical scores after infection of pigs with CSFV strain '11722-WIL'. 


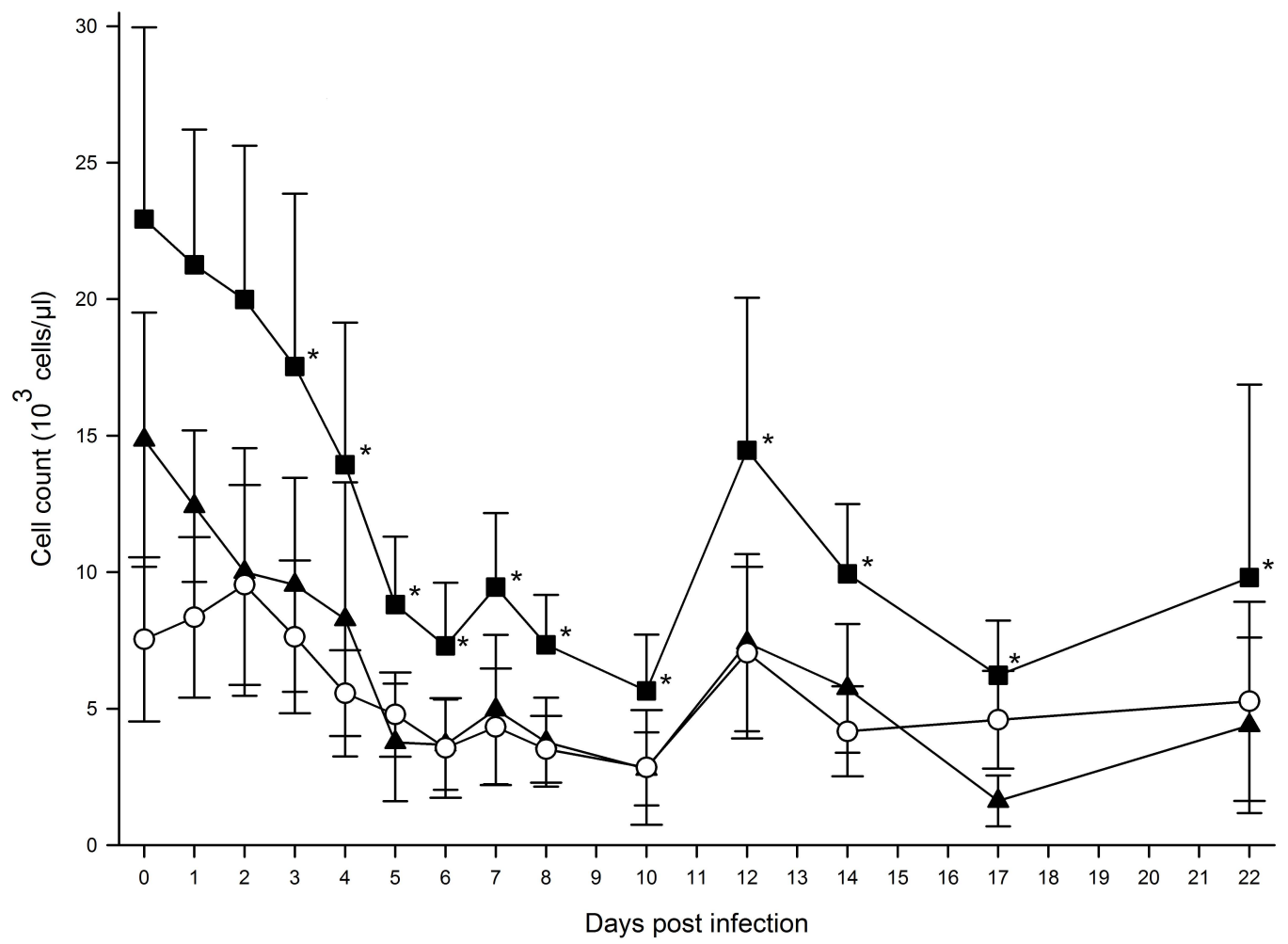

Fig. (2). Changes in mean peripheral blood leucocyte (PBL) (๘), neutrophil ( $\mathbf{\Delta})$ and lymphocyte (o) population counts from days 0 to 22 following infection of pigs with CSFV strain '11722-WIL. An asterisk indicates PBL counts significantly different from the initial population (day 0).

Table 1. Distribution of CSFV '11722-WIL' Strain in Tissues and Blood as Detected by Virus Isolation and Real-Time RT-PCR Assays Between 0 to 8 Days Post Infection

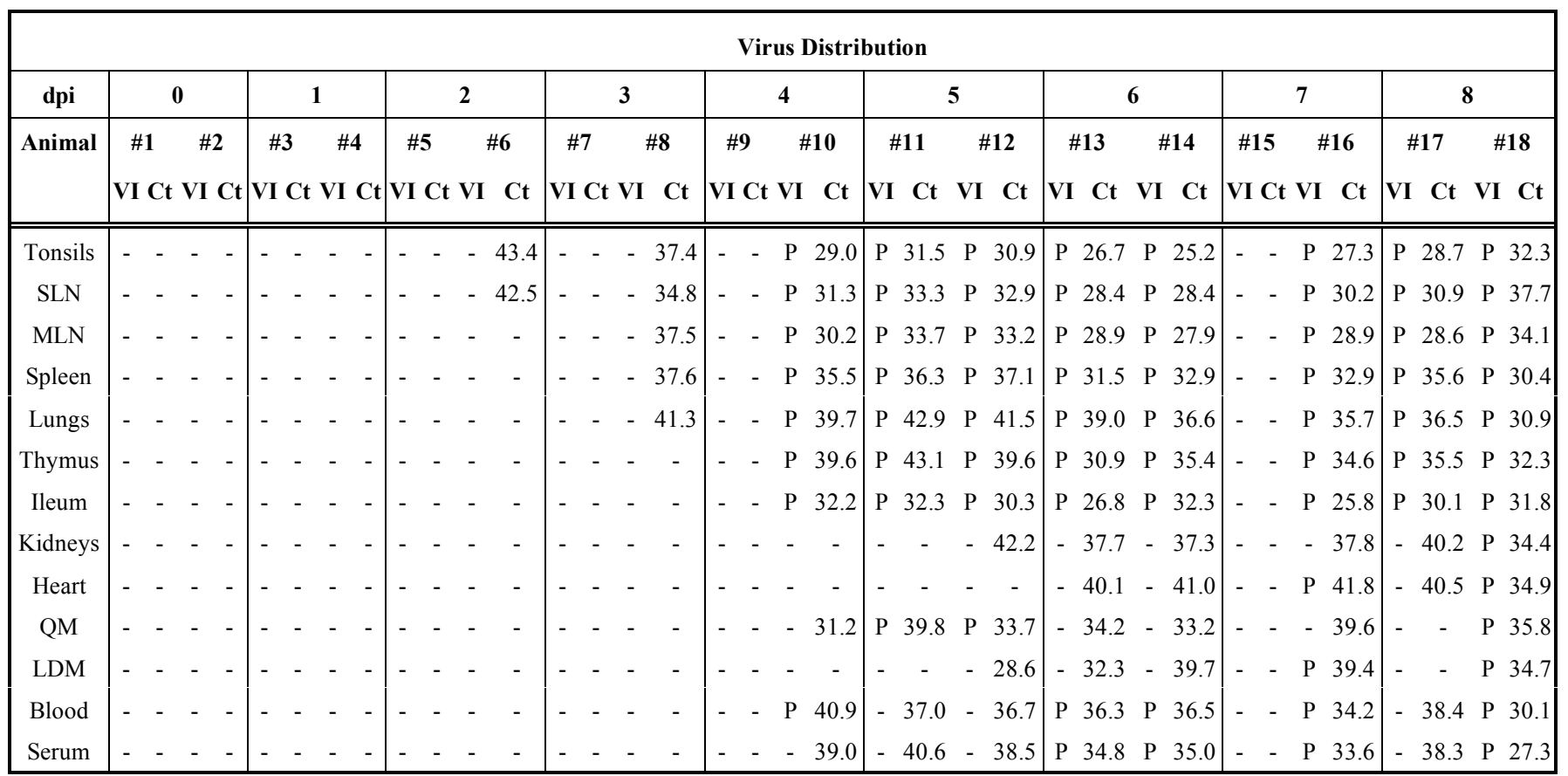

dpi: days post infection, VI: virus isolation, Ct: cycle threshold, -: negative, P: VI positive, SLN: submandibular lymph nodes, MLN: mesenteric lymph nodes, QM : quadriceps muscle, LDM : longissimus dorsi muscle. 
Table 2. Distribution of CSFV '11722-WIL' Strain in Blood as Detected by Virus Isolation and Real-Time RT-PCR Assays Post Infection

\begin{tabular}{|c|c|c|c|c|c|c|c|c|c|c|c|c|c|c|}
\hline \multirow[b]{2}{*}{ dpi } & \multicolumn{14}{|c|}{ Percentage of Blood Samples Positive by Real-Time RT-PCR and Virus Isolation in Cell Culture } \\
\hline & 0 & 1 & 2 & 3 & 4 & 5 & 6 & 7 & 8 & 10 & 12 & 14 & 17 & 24 \\
\hline Real-time RT-PCR & 0 & 0 & 3.8 & 8.3 & 59.1 & 85.0 & 88.9 & 93.7 & 100 & 100 & 100 & 100 & 100 & 100 \\
\hline VI (1 passage) & 0 & 0 & 0 & 0 & 9.1 & 35.0 & 83.3 & 87.5 & 92.9 & 100 & 100 & 87.5 & 80.0 & 100 \\
\hline $95 \%$ CI on relative sensitivity & & & - & - & $1.92-45.4$ & $18.4-67.1$ & $69.8-99.8$ & $68.1-99.8$ & & & & & & \\
\hline
\end{tabular}

dpi: days post infection, VI: virus isolation, CI: Confidence interval.

\section{Virus Detection in Blood Samples}

The first TaqVet CSF positive blood sample was found at 2 dpi (Table 2). The same sample was also detected rRTPCR positive when included in a pool of 5 blood samples. Two days later, 13 animals (59.1\%) were scored positive by this assay and two of them represented the first VI positive blood samples. At that date, two additional passages on cell culture increased the number of VI positive pigs from 2 to 9. From 5 to $8 \mathrm{dpi}$, the percentage of animals positive by rRTPCR blood examination increased from $85 \%$ to $100 \%$. In the same interval, this percentage increased from $35 \%$ to $92.9 \%$ after one passage on cell culture, and from $75 \%$ to $100 \%$ after three passages. The relative sensitivity of VI compared to rRT-PCR reached its lowest value before $6 \mathrm{dpi}(15.4 \%$ with $95 \%$ CI of $1.92-45.4$ at 4 dpi and $41.2 \%$ with $95 \%$ CI of 18.4-67.1 at $5 \mathrm{dpi}$ ). From that day onwards, both methods reached comparable levels of sensitivity (93.8\% with $95 \%$ CI of $69.8-99.8$ and $93.3 \%$ with $95 \%$ CI of $68.1-99.8$ at 6 and 7 dpi respectively). After $10 \mathrm{dpi}$ and until the end of the experiment, all collected blood samples were positive by both rRT-PCR and VI, except for one animal that became VI negative at 14 and $17 \mathrm{dpi}$, even after three passages on cell culture. As expected, all the VI positive samples were positive with the TaqVet CSF kit. In addition, all tested pools, including one rRT-PCR positive and 4 negative blood samples, were identified as positive by the same technique.

\section{Serological Finding and Effect on Virological Detection}

Serological conversion was observed from $14 \mathrm{dpi}$. At this date, one animal of the eight remaining became antibody positive in the virus neutralisation test using the homologous strain (antibody titre 1/40) (Table 3). Three days later, the neutralising antibody titre of this animal had increased $(1 / 80)$ and the blocking antibody $(\mathrm{Ab})$ ELISA also became positive (46.4\% blocking). At the same date, the blocking Ab ELISA gave a doubtful result for a second animal but no neutralising antibodies were detected. As those pigs were humanely killed or died at 17 and 22 dpi, serological conversion could not be followed any further.

The blood samples collected at 14 and 17 dpi from the animal with neutralising antibodies were rRT-PCR positive but VI negative, even after three passages on cell culture. Additional analysis of blood samples, collected at 12, 14 and 17 dpi from the same animal, was performed using the triple RT-PCR tests panel. The blood sample from 12 dpi was posi- tive by VI and rRT-PCR but negative for antibody and therefore served as a positive control in the panel of triple tests. As expected, all the RT-PCR tests with the panel were positive for this sample, providing further confirmation of the presence of a complete virus genome. Identical results were obtained for the complete panel of RT-PCR tests with the two samples collected at 14 and $17 \mathrm{dpi}$, which scored rRTPCR positive and VI negative.

Table 3. Detection of CSFV '11722-WIL' Strain in Blood Samples Yielding Discrepant Results at Later Stages of Disease

\begin{tabular}{|l||ccc|}
\hline \multicolumn{1}{|l||}{ Animal \#26 } & \multicolumn{3}{c|}{ Sample Characterisation } \\
\hline \multicolumn{1}{|c|}{ dpi } & $\mathbf{1 2}$ & $\mathbf{1 4}$ & $\mathbf{1 7}$ \\
\hline \hline VN & Negative & $1 / 40$ & $1 / 80$ \\
Antibody ELISA & Negative & Negative & Positive \\
(\% Blocking) & 28.88 & 27.92 & 46.4 \\
(cut-off 40\%) & & & \\
Virus isolation & Positive & Negative & Negative \\
Real-time RT-PCR (Ct) & 27.0 & 26.2 & 26.2 \\
Triple RT-PCR panel & Positive & Positive & Positive \\
\hline
\end{tabular}

dpi: days post infection, VN: virus neutralisation, Ct: cycle threshold.

\section{DISCUSSION}

The TaqVet CSF kit, similarly to other rRT-PCR assays is a powerful diagnostic tool available for the detection of CSFV infection in animals [12-14, 18]. In our experiment, the relative sensitivity of the rRT-PCR assay was always higher compared to VI, particularly at the earlier stages of infection. This may be explained by the very low detection limits of the assay [20]. The rRT-PCR assay allowed virus detection two days earlier than VI. At the opposite of VI the CSFV detection was achieved in the late infection stage by RT-PCR methods despite the presence of neutralising antibodies, as previously reported $[12,25]$. Moreover, this applicability in virus detection was observed regardless of the biological material analysed and the course of the disease influenced by several factors like the virulence of the strain [1] or the breed of the animal [27].

The influence of the virus distribution on the applicability of rRT-PCR was investigated using tissue and blood 
samples sequentially collected post-infection. The present virus distribution confirmed those described in immunohistological studies with high, moderate and low virulent strains [28]. CSFV genome was detected in the tonsils, which constitute the initial site of replication after oronasal infection $[11,24]$, from 2 dpi and before any other tissue or blood. This detection occurred at a very early infection stage during the incubation phase and before any clinical sign, fever or leucopaenia, in agreement with other studies [13, 18, 24]. Regarding the distribution observed in this study on pairs of slaughtered pigs, genome detection in blood or sera samples was delayed by up to 2 days compared to the tonsils at the earlier stages of infection. Virus detection in quadriceps and longissimus dorsi muscles was always preceded by viraemia and the $\mathrm{Ct}$ values were markedly higher than those obtained in blood or tonsils suggesting a lower viral load. Furthermore, the virus still remains detectable in the tonsils during the clinical phase until the late stages of infection $[12,13$, 18]. As reported by Le Dimna et al., viral genome detection by rRT-PCR was reported in tonsils as late as $\mathbf{5 8}$ days after contact infection, even when only mild forms of CSF (e.g. transient or subclinical infections) are observed [20]. In blood, the viraemia is generally limited to about 15 days in transient or subclinical infections $[9,12,14]$.

Based on the observed virus distribution the tonsils should be recommended as the target material for CSF confirmation with the rRT-PCR assay when individual diagnosis is required. Similarly, the CSFV prevalence in wild boar populations may be determined more efficiently by the rRTPCR investigation of the tonsils compared to blood or spleen, based on the distribution and the persistence of the virus. Furthermore, this study supports previous findings regarding the poor reliability of muscles for sensitive and early monitoring of CSFV contamination in meat products that could lead to false negative results, especially when low virulent strains are involved [17].

In herd surveillance programmes and for mass investigation, combined virological and serological investigations provide early and late detection of virus infection, respectively [12]. For virological surveillance, blood collected from living animals is most often proposed as an alternative to tonsil collection from a reduced number of slaughtered animals due to its ease of collection and availability in living animals $[12,20]$ In this study, the TaqVet CSF rRT-PCR kit detected CSFV genome in the tonsils of one animal as early as 2 dpi and, simultaneously, in individual and pooled (5) blood samples from the entire animal group, in accordance with previous studies [12-14]. Furthermore, viraemia was gradually observed in an increasing number of animals in the group, due to the variable susceptibility of animals to CSFV that can also explain the animal found negative at $7 \mathrm{dpi}$. The present results also clearly emphasise the need for large sampling sizes for efficient herd surveillance using rRT-PCR on blood.

Reduction of PCR sensitivity in pools of blood samples, with the higher impact during the beginning of the viraemic period, has been described with other infectious agents [29, 30]. At the opposite, no reduction in detection sensitivity was observed with the TaqVet CSF kit after pooling of 5 blood samples in the present and a previous validation study [20]. During outbreaks collected biological materials gener- ally contains non limitative viral load. In such cases, the pooling strategy will offer a convenient solution to reduce costs and working time and to increase testing capacities of the laboratory $[9,20,21]$. On the other hand, due to the reduced detection sensitivity and increased risk of false negatives [29], pooling should not be advised to investigate suspected cases or certify import-export samples which requires essentially a sensitive diagnosis $[9,31]$. In situations where the prevalence is low, most samples are expected to test negative, mostly if the sampling is performed at the very first days of the primary infection [21, 29, 31, 32]. However, a close follow of herds by the repeated analysis of pool samples at regular period will allow the surveillance of an increased number of herds and thereby simultaneously increase the probability of detecting infected herds, without drastically enlarging the number of performed analyses [21,31].

In conclusion, based upon the results obtained it was clearly demonstrated that the commercial TaqVet CSF rRTPCR provided improved CSFV detection, a more sensitive detection of CSFV, compared to virus isolation, at both the individual pig and group level. The virus was more frequently detected in the tonsils, than in other tissues, including muscles or blood, making it the most appropriate tissue for diagnostic evaluation. On the other hand, blood can be used as an acceptable alternative for early CSFV detection at the herd level. However, in order to compensate for the lower probability of detecting virus in blood during the early stages of infection, the investigation of an increased number of animals is recommended. The rRT-PCR investigations of pooled blood samples could be advisable during outbreaks or for surveillance of herds.

\section{ACKNOWLEDGEMENTS}

We would like to thank Prof. Sándor Belák, Dr Michael O'Connor and Dr Thierry van den Berg for suggestions, discussions, and critical comments. We are also grateful to R. Debaugnies, M. -L. Denne, F. Jebbari and C. Thoraval at the VAR and the laboratory team at the DVMP for technical support and we address a special thanks to the technicians at the DVMP for excellent animal care. This study was funded by the European Union in the FP6 project CSFVACCINE \& WILDBOAR (SSP1- 501599).

\section{REFERENCES}

[1] Horst HS, Huirne RB, Dijkhuizen AA. Risks and economic consequences of introducing classical swine fever into The Netherlands by feeding swill to swine. Rev Sci Tech 1997; 16(1): 07-14.

[2] Meuwissen MP, Horst SH, Huirne RB, Dijkhuizen AA. A model to estimate the financial consequences of classical swine fever outbreaks: principles and outcomes. Prev Vet Med 1999; 42(3-4): 24970.

[3] Elber AR, Stegeman A, Moser H, Ekker HM, Smak JA, Pluimers FH. The classical swine fever epidemic 1997-1998 in The Netherlands: descriptive epidemiology. Prev Vet Med 1999; 42(3-4): 15784.

[4] Ribbens S, Dewulf J, Koenen F, Laevens H, de Kruif A. Transmission of classical swine fever. A review. Vet Q 2004; 26(4): 146-55. Ribbens S, Dewulf J, Koenen F, Maes D, de Kruif A. Evidence of indirect transmission of classical swine fever virus through contacts with people. Vet Rec 2007; 160(20): 687-90.

[6] Floegel-Niesmann G, Bunzenthal C, Fischer S, Moennig V. Virulence of recent and former classical swine fever virus isolates evaluated by their clinical and pathological signs. J Vet Med B Infect Dis Vet Public Health 2003; 50(5): 214-20. 
[7] Greiser-Wilke I, Fritzemeier J, Koenen F, et al. Molecular epidemiology of a large classical swine fever epidemic in the European Union in 1997-1998. Vet Microbiol 2000; 77(1-2): 17-27.

[8] Kaden V, Lange E, Polster U, Klopfleisch R, Teifke JP. Studies on the virulence of two field isolates of the classical swine fever virus genotype 2.3 rostock in wild boars of different age groups. J Vet Med B Infect Dis Vet Public Health 2004; 51(5): 202-8.

[9] Dewulf J, Koenen F, Mintiens K, Denis P, Ribbens S, de Kruif A. Analytical performance of several classical swine fever laboratory diagnostic techniques on live animals for detection of infection. J Virol Methods 2004; 119(2): 137-43.

[10] Laevens H, Koenen F, Deluyker H, Berkvens D, de Kruif A. An experimental infection with classical swine fever virus in weaner pigs. I. Transmission of the virus, course of the disease, and antibody response. Vet Q 1998; 20(2): 41-5.

[11] Van Oirschot JT. Classical swine fever (Hog Cholera). In: Straw BE, D'Allaire S, Mengeling WL, Taylor DJ, Eds. Diseases of Swine. 8th ed. Ames, Iowa, USA: WileyBlackwell, Iowa State University Press, 1999; 159-72.

[12] Depner K, Hoffmann B, Beer M. Evaluation of real-time RT-PCR assay for the routine intra vitam diagnosis of classical swine fever. Vet Microbiol 2007; 121(3-4): 338-43.

[13] Ophuis RJ, Morrissy CJ, Boyle DB. Detection and quantitative pathogenesis study of classical swine fever virus using a real time RT-PCR assay. J Virol Methods 2006; 131(1): 78-85.

[14] Uttenthal A, Storgaard T, Oleksiewicz MB, de Stricker K. Experimental infection with the Paderborn isolate of classical swine fever virus in 10-week-old pigs: determination of viral replication kinetics by quantitative RT-PCR, virus isolation and antigen ELISA. Vet Microbiol 2003; 92(3): 197-212.

[15] Edwards S. Survival and inactivation of classical swine fever virus. Vet Microbiol 2000; 73(2-3): 175-81.

[16] Krassnig R, Schuller W, Heinrich J, Werfring F, Kalaus P, Fruhwirth M. [Isolation of the agent of European swine plague from imported frozen wild boar meat]. Dtsch Tierarztl Wochenschr 1995; 102(1): 56.

[17] Thur B, Hofmann MA. Comparative detection of classical swine fever virus in striated muscle from experimentally infected pigs by reverse transcription polymerase chain reaction, cell culture isolation and immunohistochemistry. J Virol Methods 1998; 74(1): 4756.

[18] Handel K, Kehler H, Hills K, Pasick J. Comparison of reverse transcriptase-polymerase chain reaction, virus isolation, and immunoperoxidase assays for detecting pigs infected with low, moderate, and high virulent strains of classical swine fever virus. J Vet Diagn Invest 2004; 16(2): 132-8.

[19] Hoffmann B, Beer M, Schelp C, Schirrmeier H, Depner K. Validation of a real-time RT-PCR assay for sensitive and specific detection of classical swine fever. J Virol Methods 2005; 130(1-2): 3644.
[20] Le Dimna M, Vrancken R, Koenen F, et al. Validation of two commercial real-time RT-PCR kits for rapid and specific diagnosis of classical swine fever virus. J Virol Methods 2008; 147(1): 13642.

[21] Koenen F, Van Caenegem G, Vermeersch JP, Vandenheede J, Deluyker H. Epidemiological characteristics of an outbreak of classical swine fever in an area of high pig density. Vet Rec 1996; 139(15): 367-71.

[22] Aguero M, Fernandez J, Romero L, Sanchez Mascaraque C, Arias M, Sanchez-Vizcaino JM. Highly sensitive PCR assay for routine diagnosis of African swine fever virus in clinical samples. J Clin Microbiol 2003; 41(9): 4431-4.

[23] Letellier C, Kerkhofs P. Real-time PCR for simultaneous detection and genotyping of bovine viral diarrhea virus. J Virol Methods 2003; 114(1): 21-7.

[24] Mittelholzer C, Moser C, Tratschin JD, Hofmann MA. Analysis of classical swine fever virus replication kinetics allows differentiation of highly virulent from avirulent strains. Vet Microbiol 2000; 74(4): 293-308.

[25] Haegeman A, Dewulf J, Vrancken R, Tignon M, Ribbens S, Koenen F. Characterisation of the discrepancy between PCR and virus isolation in relation to classical swine fever virus detection. J Virol Methods 2006; 136(1-2): 44-50.

[26] Jensen MH. Detection of antibodies against hog cholera virus and bovine viral diarrhea virus in porcine serum. A comparative examination using CF, PLA and NPLA assays. Acta Vet Scand 1981; 22(1): 85-98.

[27] Depner KR, Hinrichs U, Bickhardt K, et al. Influence of breedrelated factors on the course of classical swine fever virus infection. Vet Rec 1997; 140(19): 506-7.

[28] Narita M, Kawashima K, Kimura K, et al. Comparative immunohistopathology in pigs infected with highly virulent or less virulent strains of hog cholera virus. Vet Pathol 2000; 37(5): 402-8.

[29] Munoz-Zanzi CA, Johnson WO, Thurmond MC, Hietala SK. Pooled-sample testing as a herd-screening tool for detection of bovine viral diarrhea virus persistently infected cattle. J Vet Diagn Invest 2000; 12(3): 195-203.

[30] Rovira A, Clement T, Christopher-Hennings J, et al. Evaluation of the sensitivity of reverse-transcription polymerase chain reaction to detect porcine reproductive and respiratory syndrome virus on individual and pooled samples from boars. J Vet Diagn Invest 2007; 19(5): 502-9.

[31] Klinkenberg D, Nielen M, Mourits MC, de Jong MC. The effectiveness of classical swine fever surveillance programmes in The Netherlands. Prev Vet Med 2005; 67(1): 19-37.

[32] Munoz-Zanzi C, Thurmond M, Hietala S, Johnson W. Factors affecting sensitivity and specificity of pooled-sample testing for diagnosis of low prevalence infections. Prev Vet Med 2006; 74(4): 309-22. 